\title{
Analisis Penerapan Media Google Form Untuk Meningkatkan Minat Dan Hasil Belajar Matematika Peserta didik Program Multimedia SMK Islam Perti Jakarta
}

\author{
M. Ardiansyah \\ Universitas Indraprasta PGRI \\ m.ardiansyah_unindra@yahoo.co.id
}

Abstrak: Penelitian ini adalah survey terhadap 22 peserta didik dengan media pembelajaran google form. Populasi untuk penelitian adalah peserta didik SMK Islam Perti Jakarta. Sampling di pilih dengan metode purposive sampling, yaitu peserta didik kelas X MM angkatan 2019 pada materi ukuran pemusatan data tunggal. Metode yang digunakan adalah kualitatif deskriptif. Instrumen penelitian berupa soal yang terdiri atas 15 essay. Penelitian ini bertujuan untuk mnganalisis minat dan hasil belajar peserta didik program Multimedia di SMK Islam Perti Jakarta matapelajaran matematika melalui media pembelajaran google form. Penelitian dilaksanakan di SMK Islam Perti dengan subyek penelitian kelas X MM berjumlah 22 peserta didik dan objek penelitian pada mata pelajaran matematika. Hasil penelitian menunjukkan bahwa terdapat peningkatan minat dan hasil belajar matematika dari kondisi awal yang diajarkan dengan metode ceramah dan powerpoint. Simpulannya bahwa penggunaan media pembelajaran Google Form dapat meningkatkan minat dan hasil belajar matematika peserta didik kelas X MM pada matapelajaran matematika.

Kata Kunci: google form, minat dan hasil belajar matematika

\section{Pendahuluan}

Pembelajaran merupakan suatu usaha pendidik dalam menciptakan unsur positif dalam proses transfer ilmu, sehingga secara langsung dapat memperhatikan tingkat minat peserta didik dalam penerimaan ilmu. Media dalam kaitannya sebagai unsur yang dapat pendukung pencapaian tujuan penerimaan ilmu. Hal ini diungkapkan Adam dan Syastra (2015) "media pembelajaran merupakan semua bentuk berupa materi maupun nonfisik dalam sebuah penyampaian pengetahuan yang diperlukan dalam menunjang kegiatan pendidik sehingga menyederhanakan konsep atau materi kepada peserta didik. Adapun sistem media pembelajaran yang dijadikan tolak ukur pendidik adalah bagaimana pengaplikasiannya dapat diterima secara utuh oleh peserta didik.

Proses interaksi antara pendidik dan peserta didik tentunya harus ada. Dalam proses inilah pendidik harus bisa dalam mengopeasikan computer dalam rangka meningkatkan potensi dan jati dirinya. Pendidik disini bukan berarti hanya mengajarkan dengan teknik yang sederhana dan manual, akan tetapi harus bisa menakar dan terus menggali apa yang berkembang pada posisi sekarang. Baik itu metode maupun media yang nantinya akan disampaikan kepada peserta dididiknya. Penggunaan media dalam proses transfer pengetahuan tersebut dapat menjadi pijakan awal dalam mempercepat hubungan antara pengajar dengan penerima ilmu sehingga nantinya akan terasa sangat bermanfaat dalam rangka peningkatan kualitas pendidikan (Tafonao, 2018).

Minat belajar dapat tercapai tergantung kemampuan pendidik dalam manajemen pembelajaran. Minat akan sesuatu dipelajari dan dapat berdampak pada aksi belajar berikutnya serta dapat berakibat pada respon minat yang terbaru. Minat akan sesuatu hal merupakan hasil dari belajar yang dapat menopang belajar berikutnya (Slameto, 2013). Defenisi minat adalah segala rasa lebih menyukai, rasa ketertarikan ana sesuatu (Fauziah et al., 2017). Minat merupakan sebagai subjek related affect, yang isinya termasuk minat dan perilaku terhadap berbagai materi pembelajaran (Susanto, 2015). Untuk anak muda, minat dalam suatu event tertentu berjangka pendek sekali, sewaktu-waktu dapat berpindah dengan demikian dia menginginkan sebuah aktivitas. Dia akan terus memfokuskan kegiatannya kepada pilihan dari hatinya dan lebih menyukai dalam memperjuangkan apa yang dia kehendaki dibandingkan yang lain (Syaiful Bahri Djamarah, 2011). Minat mempunyai beberapa 
dampak yang signifikan pada ketuntasan belajar, tingkatan minat lanjut akan mempengaruhi tingkat perhatian dan kesuksesan peserta didik berpartisipasi dalam pembelajaran sehingga nantinya memunculkan kemungkinan keberhasilan dalam diri seseorang (Nurhasanah \& Sobandi, 2016).

Pemanfaatan teknologi dalam proses transfer dan penerimaan ilmu pastinya akan diutamakan agar pemahaman suatu konsep dapat dipelajari dengan baik. Penggunaan teknologi merupakan sesuatu yang nantinya pengguna dapat melaksanakan pekerjaannya berlandaskan pada kesungguhan, frekuensi pemanfaatan dan banyak aplikasi atau piranti lunak yang dapat dimanfaatkan (Rahmawati, 2012).

Pendidik harus senantiasa aktif dan reaktif dalam melakukan sebuah pengembangan diri khususnya konteks interaksi belajar matematika. Menurut Arifin (2012) mengatakan fungsi terhadap pengembangan penilaian adalah untuk menyelaraskan tingkatan peserta didik, keaktifannya dalam menghadapi setiap program sekolah, mendorong kemajuan aktivitas dan inovatif peserta didik.

Pendidik harus menetapkan bentuk evaluasi yang akan diterapkan pada proses belajar matematika. Model evaluasi matematika tidak selamanya berbentuk test, melaikan juga dalam format penetapan tugas kelas, memfungsikan aktivasi dalam diskusi, dan mengutarakan ide dan gagasan. test hanya formalitas model evaluasi penilaian, akan tetapi sering dimanfaatkan oleh pendidik. Hasil belajar matematika merupakan dasar perubahan sikap tingkah laku peserta didik yang mencakup pespektif pengetahuan, sikap, dan tingkahlaku selepas menyelesaikan aktivitas belajar matematika dimana kuantitas dan kualitasnya dipengaruhi oleh elemen yang tertata dalam sanubari peserta didik dan lingkungan kehidupan yang mengontrolnya (Lestari, 2015).

Tugas maupun penilaian mulai beralih dari penggunaan kertas ulangan (PBT) berubah jadi penialaian tugas dan ulangan berbasis Teknologi atau familiar dengan CBT. Peluncuran sistem CBT di negara Indonesia sudah diapresiasi tahun 2007. Pemanfaatan CBT yang difungsikan sebagai media evaluasi penilaian diplot sangat efisien dan ekonomis kalau ditandingkan dengan PBT (Jimoh et al., 2012).

Pemanfaatan media pembelajaran online berbasis teknologi banyak diaplikasikan di dunia pendidikan. Penawaran berbagai macam aplikasi dapat dengan sangat mudah diakses via internet. Beberapa aplikasi tersebut dapat diterusan dengan lancar memanfaatkan gadget. Contoh yang bisa diaplikasikan tentang media pembelajaran ialah google form. Google Form merupakan salah satu unit elemen google docs yang telah dipersiapkan oleh Google. Google Form merupakan perangkat lunak gratis diperuntukan oleh semua kalangan dan dapat diakses dengan mudah dalam pengoperasiannya (Purwati \& Nugroho, 2018).

Pemanfaatan berbagai media pembelajaran kreatif disekolah kejuruan kenyataannya masih minus dan terkesan mebuat peserta didik malas, termasuk peruntukannya dalam media pembelajaran matematika. Pendidik matematika di SMK Islam Perti sangat kaku dalam mengaplikasikan setiap media penilaian aplikasi CBT dan menentukan tetap penilaian manual dengan kertas, Kendati perlengkapan sekolah dalam melaksanakan penilaian pembelajaran model CBT memadai. Sekolah telah dilengkapi berbagai akomodasi wifi dan internet $100 \mathrm{mbps}$ yang dapat diperuntukan untuk proses belajar matematika (Purwati \& Nugroho, 2018). Sebagian besar peserta didik mempunyai perangkat smartphone android yang dapat mendukung dalam ketercapaian terlaksananya proses pembelajaran model CBT. Gadget android adalah sistem pengoperasian perangkat handphone yang sangat berkembang dikalangan masyarakat saat sekarang. Gadget android merupakan sebuah platform mempunyai karakter sumber terbuka yang dipersiapkan untuk piranti berbasis Linux yang diperuntukkan untuk mobile device (Astuti et al., 2017). Jadi penelitian ini difokuskan dalam menganalisis minat dan hasil belajar pada mata pelajaran matematika peserta didik kelas X Multimedia SMK Islam Perti Jakarta tahun ajaran 2019/2020 melalui media pembelajaran google form.

\section{Metode}

Penelitian ini adalah survey kepada 22 peserta didik dengan media pembelajaran google form. populasi penelitian adalah seluruh peserta didik kelas X SMK Islam Perti Jakarta. Teknik sampling dengan metode purposive sampling, yaitu peserta didik kelas X MM angkatan 2019 pada matapelajaran matematika. Metode yang dimanfaatkan adalah kualitatif deskriptif yakni dengan memperoleh laporan fenomena yang terjadi dengan demikian memperoleh sinopsis tentang sumber teliti dalam keadaan dan kurun waktu tertentu. Piranti dalam penelitian berbentuk soal konsep matematika 15 isian. Soal yang dimanfaatkan dalam penelitian adalah soal 
yang berkaitan dengan matapelajaran matematika yang diajarkan saat itu. Kategori minat belajar dilihat pada Tabel berikut.

Tabel 1. Kategori minat belajar

\begin{tabular}{ccc}
\hline No & Uraian & Kategori \\
\hline 1. & $0 \leq x \leq 29 \%$ & Sangat rendah \\
2. & $30 \%<x<59 \%$ & Rendah \\
3. & $60 \%<x \leq 79 \%$ & Sedang \\
4. & $80 \%<x \leq 100 \%$ & Tinggi \\
\hline
\end{tabular}

\section{Hasil dan Pembahasan}

Pada situasi sebelumnya minat dan hasil belajar X MM berada pada kategori sangat rendah, peserta didik dalam menerima pengetahuan di kelas masih kurang bersemangat. Peserta didik masih malu-malu menyampaikan gagasan, retorika dan berlatih dengan soal matematika. Kondisi tersebut dapat diformulasikan tolak ukur dalam rangka menguatkan serta meningkatkan minat dan hasil belajar peserta didik. Berikut tabel minat dan hasil belajar peserta didik kelas X jurusan multimedia.

Tabel 2. Minat Belajar matematika Peserta didik Pada Observasi Awal

\begin{tabular}{ccccc}
\hline No & Kelas & Jumlah peserta didik & Persentase minat belajar matematika & Kritria \\
\hline 1 & X MM & 44 & $29 \%$ & Sangat Rendah \\
2 & X AKL 1 & 40 & $52 \%$ & Rendah \\
3 & X AKL 2 & 32 & $48 \%$ & Rendah \\
4 & X OTKP 1 & 46 & $44 \%$ & Rendah \\
5 & X OTKP 2 & 45 & $51 \%$ & Rendah \\
6 & X OTKP 3 & 45 & $54 \%$ & Rendah \\
\hline
\end{tabular}

Tabel 3. Hasil Belajar matematika Peserta didik Pada Observasi Awal

\begin{tabular}{|c|c|c|c|c|}
\hline No & Kelas & Jumlah peserta didik & Rata-rata nilai matematika & Kritria \\
\hline 1 & X MM & 44 & 52 & Cukup \\
\hline 2 & $\mathrm{X} \cdot \mathrm{AKL} 1$ & 40 & 74 & Baik \\
\hline 3 & X.AKL 2 & 32 & 63 & Sedang \\
\hline 4 & X OTKP 1 & 46 & 60 & Sedang \\
\hline 5 & X OTKP 2 & 45 & 72 & Baik \\
\hline 6 & $\mathrm{X}$ OTKP 3 & 45 & 78 & Baik \\
\hline
\end{tabular}

Berdasarkan data tersebut, persentase minat belajar paling tinggi pada OTKP 3 dan skor paling rendah pada kelas Multimedia. Hasil belajar pada kondisi awal, menunjukkan nilai rata-rata matematika paling tinggi terdapat pada kelas OTKP 3 dengan nilai 78 dan paling rendah Multimedia dengan nilai rata-rata 52. Hasil penelitian awal itu membuktikan bahwa minat dan hasil belajar matematika terendah berada pada kelas Multimedia.

Pelaksanaan penelitian dengan menggunakan media pembelajaran google form dilakukan pada jam pelajaran matematika. Aktivitas penelitian untuk memperoleh minat belajar matematika peserta didik ialah mendownload materi, menulis pertanyaan, mengunggah hasilnya dalam google form, saling menanggapi permasalahan, mengumpulkan yang sudah dikerjakan tepat waktu, sebelum waktu diakhiri oleh pendidik, dan mengerjakan soal yang terdapat dalam aplikasi google form. Hasil penelitian minat belajar matematika dengan media google form menunjukkan adanya peningkatan minat belajar dan rasa tertarik untuk lebih memahami pelajaran matematika.

Berdasar hasil pemeparan pada tabel 4, minat belajar matematika peserta didik memperlihatkan adanya suatu perkembangan dari hasil kondisi awal dengan media pembelajaran konvensional. Total kondisi awal sebesar 42\% dengan kategori kurang aktif, mengalami kenaikan signifikan menjadi 81\% setelah mengaplikasikan google form dengan kategori sangat aktif. 
Tabel 4. Data Hasil penelitian minat Belajar dengan media google form

\begin{tabular}{clccc}
\hline \multirow{2}{*}{ No } & \multicolumn{1}{c}{ Indikator } & $\begin{array}{c}\text { Media pembelajaran } \\
\text { Konvensional }\end{array}$ & $\begin{array}{c}\text { Media } \\
\text { powerpoint }\end{array}$ & $\begin{array}{c}\text { Media google } \\
\text { form }\end{array}$ \\
\hline 1 & Mengunduh bahan ajar & $30 \%$ & $46 \%$ & $68 \%$ \\
2 & Merumuskan pertanyaan & $40 \%$ & $57 \%$ & $76 \%$ \\
3 & Mengunggah hasil tugas matematika ke google & $44 \%$ & $58 \%$ & $80 \%$ \\
& form & & & \\
4 & Memberikan tanggapan & $46 \%$ & $56 \%$ & $85 \%$ \\
5 & Mengumpulkan tugas tepat waktu & $50 \%$ & $63 \%$ & $92 \%$ \\
6 & Mengerjakan soal melalui google form & $41 \%$ & $50 \%$ & $82 \%$ \\
\hline & Rata-rata & $42 \%$ & $55 \%$ & $81 \%$ \\
\hline
\end{tabular}

Hasil belajar matematika dengan menggunakan google form membuktikan adanya peningkatan dari sebelumnya. Berdasar penilaian pembelajaran yang dilakukan dengan mengerjakan 15 soal matematika diperoleh hasil belajar matematika rata-rata nilai 66 dengan media powerpoint dan 84 dengan media google form. Hal ini menunjukkan terdapat peningkatan yang signifikan dari kondisi awal rata-rata nilai matematika.

Tabel 5. Hasil Belajar Peserta didik

\begin{tabular}{cc}
\hline Uraian & Nilai rata-rata \\
\hline Kondisi Awal & 52 \\
Powerpoint & 66 \\
Google form & 84 \\
\hline
\end{tabular}

(Sumber : Data primer diolah)

\section{Pembahasan}

Hasil observasi memperlihatkan pemanfaatan media google form dapat menambah minat serta hasil dari belajar pada matapelajaran matematika peserta didik. Minat belajar peserta didik berupa medownload materi, menanyakan pertanyaan, mengunggah hasil tugas yang diberikan, memberikan sebuah tanggapan sesuai hasil yang diperoleh, mengumpulkankannya tepat waktu dan mengerjakan soal-soal berkonstribusi dari kategori kurang aktif berubah sangat aktif. Hasil belajar matematika peserta didik dapat mencapai ketuntasan kelas yaitu rata-rata nilai 84 mampu mencapai KKM yaitu 75. Hal ini meunjukkan bahwa hipotesis penelitian tercapai. Hal ini sesuai dengan penelitian Rachmat \& Krisnadi (2020) Efektifitas pembelajaran daring dengan aplikasi google form sangat baik untuk diterapkan. Selain itu hasil penelitian Mardiana \& Purwanto (2017) "Google Form dinilai mampu dijadikan sebagai alternatif pembuatan evaluasi belajar peserta didik, hal ini dibuktikan dengan hasil 100\% guru mempunyai rasa tertarik untuk penggunaan google form”. Selain itu, penelitian Iqbal et al. (2018) "the use of Google forms as a learning medium is very easy to understand, including the steps for making questions, worksheets with preparation, design and implementation stages, some of the LK models produced are narrative, audio-visual and link models". Hasil penelitian dalam model kuantitatif yang diperoleh dalam bentuk tabel angka, deskripsi, grafik. Sedangkan hasil observasi dalam bentuk model kualitatif yang bersumber dari wawancara, penafsiran, pengamatan, dan lain-lain dibuat ke dalam ringkasan substansial yang disajikan dalam bentuk tabel-tabel deskriptif.

\section{Simpulan}

Penggunaan media pembelajaran google form pada peserta didik program multimedia di SMK Islam Perti Jakarta dapat berkonstribusi dalam minat serta hasil belajar matematika peserta didik. Skor minat belajar matematika dengan menggunakan metode sebelumnya hanya sebesar 29\% dan setelah menggunakan media google form sebesar $81 \%$. Pemanfaatan media pembelajaran google form tentunya dapat meningkatkan hasil belajar matematika peserta didik. Hasil belajar matematika dengan menggunakan media konvensional mempunyai nilai rata-rata 52, sedangkan setelah mengaplikasikan media google form nilai rata-rata menjadi 84 . Hasil belajar matematika program multimedia di SMK Islam Perti Jakarta mengalami peningkatan setelah adanya penggunaan media pembelajaran google form. 


\section{Ucapan Terima Kasih}

Penulis menghaturkan terima kasih kepada Lembaga pendidikan dan pengajaran Al Islamiyah SMK Islam Perti Jakarta yang kiranya mengijinkan untuk meneliti dan peserta didik program multimedia yang sudah memberikan informasi dan waktu sebagai data peneliti.

\section{Daftar Pustaka}

Ahmad Susanto, (2015). Pemanfaatan QR Code Scanner untuk aplikasi penampil data koleksi pamer di museum negeri Sonobudoyo berbasis android. Biomass Chem Eng.

Arifin, Z. (2012). Evaluasi pembelajaran. Bandung: Remaja Rosdakarya. https://doi.org/979-692-956-2

Astuti, I. A. D., Sumarni, R. A., \& Saraswati, D. L. (2017). Pengembangan Media Pembelajaran Fisika Mobile Learning berbasis Android. Jurnal Penelitian $\mathcal{E}$ Pengembangan Pendidikan Fisika, 3(1), 57. https://doi.org/10.21009/1.03108

Fauziah, A., Rosnaningsih, A., \& Azhar, S. (2017). HUBUNGAN ANTARA MOTIVASI BELAJAR DENGAN MINAT BELAJAR SISWA KELAS IV SDN PORIS GAGA 05 KOTA TANGERANG. Jurnal JPSD (Jurnal Pendidikan Sekolah Dasar). https://doi.org/10.26555/jpsd.v4i1.a9594

Iqbal, M., Simarmata, J., Feriyansyah, F., Tambunan, A. R. S., Sihite, O., Gandamana, A., Eza, G. N., Kurniawan, F., Asiah, A., Rozi, F., Faisal, F., Manurung, I. F. U., Ihwani, M., Nathan, P. L. A., Sitanggang, N., Simbolon, N., Simanjuntak, E. B., \& Limbong, T. (2018). Using Google form for student worksheet as learning media. International Journal of Engineering and Technology(UAE). https://doi.org/10.14419/ijet.v7i2.29.13646

Jimoh, R. G., Abduljaleel, K. S., \& Kawu, Y. K. (2012). Students' Perception of Computer Based Test (CBT) for Examining Undergraduate Chemistry Courses. Journal of Emerging Trends in Computing and Information Sciences.

Lestari, I. (2015). Pengaruh Waktu Belajar dan Minat Belajar terhadap Hasil Belajar Matematika. Formatif: Jurnal Ilmiah Pendidikan MIPA, 3(2). https://doi.org/10.30998/formatif.v3i2.118

Mardiana, T., \& Purwanto, A. W. (2017). Google Form Sebagai Alternatif Pembuatan Latihan Soal Evaluasi. Universty Research Colloquium.

Nurhasanah, S., \& Sobandi, A. (2016). MINAT BELAJAR SEBAGAI DETERMINAN HASIL BELAJAR SISWA. Jurnal Pendidikan Manajemen Perkantoran, 1(1), 128. https://doi.org/10.17509/jpm.v1i1.3264

Purwati, D., \& Nugroho, A. N. P. (2018). PENGEMBANGAN MEDIA EVALUASI PEMBELAJARAN SEJARAH BERBASIS GOOGLE FORMULIR DI SMA N 1 PRAMBANAN. ISTORIA: Jurnal Pendidikan Dan Ilmu Sejarah. https://doi.org/10.21831/istoria.v14i1.19398

Rachmat, A., \& Krisnadi, I. (2020). Analisis Efektifitas Pembelajaran Daring (Online) Untuk Siswa SMK Negeri 8 Kota Tangerang Pada Saat Pandemi Covid 19. Jurnal Pendidikan.

Rahmawati, D. (2012). Analisis Faktor Faktor yang Berpengaruh Terhadap Pemanfaatan Teknologi Informasi. Jurnal Ekonomi Dan Pendidikan, 5(1). https://doi.org/10.21831/jep.v5i1.606

Slameto. (2013). Belajar dan Faktor-faktor yang Mempengaruhinya. Rineka Cipta.

Steffi Adam dan Muhammad Taufik Syastra. (2015). Pemanfaatan Media Pembelajaran Berbasis Teknologi Informasi Bagi Siswa Kelas X Sma Ananda Batam. CBIS Journal.

Syaiful Bahri Djamarah. (2011). Daftar Pustaka. In Psikologi Belajar. https://doi.org/10.1017/CBO9781107415324.004

Tafonao, T. (2018). PERANAN MEDIA PEMBELAJARAN DALAM MENINGKATKAN MINAT BELAJAR MAHASISWA. Jurnal Komunikasi Pendidikan, 2(2), 103. https://doi.org/10.32585/jkp.v2i2.113 